\title{
A arte transgênica
}

\author{
Transgenic art
}

Entrevista com

\section{Eduardo Kac}

Professor e Chefe, Art and Technology Department The School of the Art Institute of Chicago

112 S. Michigan Avenue. Chicago IL 60603

ekac@artic.edu; www.ekac.org/

Entrevista concedida a

Dolores Galindo

em 27.7.2005, em São Paulo

Pesquisadora do

Programa de Estudos Pós-

Graduados em Psicologia Social Pontifícia Universidade Católica de São Paulo

Rua Monte Alegre, 984, Perdizes 05014-901 São Paulo - SP - Brasil tinagalindo@uol.com.br
KAC, E.: A arte transgênica.

(Entrevista concedida a Dolores Galindo).

História, Ciências, Saúde - Manguinhos,

v. 13 (suplemento), p. 247-56, outubro 2006.

Nesta entrevista, o artista Eduardo Kac discute a relação entre arte plástica contemporânea, ciência e tecnologia, por meio de sua obra. Considerado um 'bioartista' desde a década de 1990, Kac busca investigar a poética da vida e da evolução, incluindo experimentações com materiais biológicos. Já nos anos 80, quando realizou sua primeira obra tele-robótica, o artista trabalhava com holografia e sistemas de telecomunicação, promovendo a ruptura de fronteiras entre humanos e máquinas.

PALAVRAS-CHAVE: bioarte; biossegurança.

KAC, E.: Transgenic art.

(Interviewed by Dolores Galindo).

História, Ciências, Saúde-Manguinhos,

v. 13 (supplement), p. 247-56, October 2006.

In this interview, artist Eduardo Kac talks about the relation between contemporary art, science, and technology as expressed in his works. Classified as a 'bioartist' since the 1990s, Kac's quest is to investigate the poetics of life and of evolution, and this includes experimentations with biological materials. The artist did his first tele-robotic work in the 1980s, working with holography and telecommunication systems to break down the boundaries between humans and machines.

KEYWORDS: bioart; biosecurity. 
A discussão em torno dos alimentos transgênicos e outros or ganismos geneticamente modificados há muito saiu do âmbito acadêmico e chegou à sociedade. Também na arte a transgenia ganhou lugar, ocupando o imaginário e a criatividade de artistas. Nesse campo, o brasileiro Eduardo Kac - atualmente ligado à School of the Art Institute of Chicago (Estados Unidos) - destaca-se entre os bioartistas da atualidade, habitando a zona fronteiriça entre arte, ciência e tecnologia.

Os trabalhos de Eduardo Kac têm sido exibidos em exposições internacionais. Em seu currículo constam obras de arte transgênicas, como GFP Bunny, um coelho fluorescente verde, e a instalação Move 36, exposta na XXVI Bienal Internacional de Arte em São Paulo, em 2004. Move 36, na opinião de seu criador, "explora as fronteiras permeáveis entre o humano e o não-humano, o vivo e o não-vivo" e faz alusão ao dramático movimento que definiu a disputa no jogo de xadrez entre uma máquina (o computador Deep Blue) e o campeão mundial Gary Kasparov em 1997.

Já "Eighth Day", exibida em 2001 na Arizona State University (Estados Unidos), é uma arte transgênica que investiga "a ecologia de criaturas fluorescentes que evoluem em nosso mundo". "Enquanto criaturas fluorescentes estão sendo desenvolvidas de forma isolada em laboratórios, vistas coletivamente elas formam o núcleo de um novo sistema bioluminescente sintético", diz o artista em seu site (www.ekac.org/), um universo que deve ser visitado pelos leitores que desconhecem a obra desse bioartista.

Numa época em que museus de arte e instituições culturais começam a incorporar a criação digital, a obra de Kac alarga os horizontes através do uso da engenharia genética como meio de criação artística.

Além de permitir discutir a interface entre ciência \& arte e os espaços de diálogo e de colaboração entre artistas e cientistas que desenvolvem trabalhos na área de biotecnologia, a obra de Kac suscita várias questões, até mesmo de fundo ético, a exemplo do que ocorre com a pesquisa científica e as aplicações tecnológicas. Quais implicações, em termos éticos e de biossegurança, são suscitadas por esse tipo de arte? Como a sociedade civil se posicionará frente a isso? Que impacto cultural a bioarte poderá ter?

Nesta entrevista, Kac fala de sua obra e de algumas questões relacionadas ao diálogo entre artistas e cientistas.

Desde os anos 80 você escreve sobre arte, tecnologia e temas correlatos. Qual o papel da mídia na elaboração do seu trabalho artístico?

$\mathrm{O}$ que eu quis fazer nos anos 80 foi ao mesmo tempo criar a obra e, em paralelo à produção das obras de arte, criar as condições para que a obra fosse recebida. Em outras palavras, criar um 
espaço crítico, um espaço de recepção da obra, e para isso escrevi regularmente para jornais - Jornal do Brasil, O Globo e Folha de S. Paulo, sobretudo. Publiquei artigos sobre arte, tecnologia, arte e tecnologia, literatura, literatura e tecnologia. Aspectos da transformação social causados pela tecnologia também me interessavam. Por exemplo, no meu livro Luz \& Letra [Rio de Janeiro, Ed. Contra Capa, 2004], que reúne os meus textos dos anos 80, há um artigo sobre a nova imagem do corpo tornada possível pelas tecnologias médicas da visualização - como termografia, ressonância magnética e tomografia. $\mathrm{O}$ artigo não era sobre arte propriamente dita, mas sobre novas maneiras de representar o corpo, que sempre foi uma questão da arte. Sempre trabalhei nesse sentido e por isso escrevi muito, tanto para criar a obra como para criar um espaço de recepção e de formação de opinião.

Como opera no cotidiano o 'fazer' de um trabalho que envolve biotecnologia? O acesso ao laboratório, a algum profissional que domine técnicas específicas...

Da mesma forma como faz qualquer artista contemporâneo. Richard Serra, ${ }^{1}$ por exemplo, trabalha com placas de metal imensas, que não cabem em um ateliê. Ele trabalha com estaleiros onde são feitos navios e tem uma equipe que faz processamento de informação. A especificidade é inerente àquilo que o artista quer fazer. A equipe vai ser sempre específica à sua prática. A vasta maioria dos artistas contemporâneos trabalha com assistentes ou equipes técnicas, especializadas na área que eles querem manipular, seja computador, vídeo, filme, fabricação de objetos, construção de ambientes, produção de dispositivos eletrônicos e assim por diante. Isto não é novidade. Tradicionalmente, artistas trabalharam com assistentes, aprendizes, equipe etc. Rafael e Rembrandt, por exemplo, tinham suas equipes. A Bioarte não é exceção.

Vocêvê alguma especificidade em trabalhar junto a cientistas? Vê alguma diferença com relação a outros colaboradores?

Sempre vai haver. No caso de Richard Serra, há uma pessoa em sua equipe que faz o cálculo para as imensas placas de metal não caírem, e, no estaleiro, engenheiros fazem as dobras de metal. Como na minha plataforma de trabalho é central a criação de seres que não existiam na natureza antes da criação de uma obra específica, isto traz questões inerentes a esse tipo de trabalho. Cada artista vai lidar com situações específicas.

\footnotetext{
${ }^{1}$ Informações sobre o artista podem ser obtidas em www.guggenheimcollection.org/ site/artist_work_md_144A_7.html.
} 
Comente um pouco sobre as especificidades desses problemas...

Cada obra tem uma singularidade, um conjunto de situações que lhe são particulares. Mas talvez o que há de comum a todas as obras seja esse processo de concepção que envolve a questão da viabilidade: "tive uma idéia, será que dá para fazer isso?". E as etapas materiais de execução? E o tempo que demora até obtermos o produto final? Já foi feito algo parecido que possa servir como referência? Não. Há garantia de que vai dar certo? Não, porque não foi feito. Há uma probabilidade de dar certo? Há. Como é possível minimizar a margem de erro? No caso de um ser vivo com sistema nervoso, é preciso ter certeza de que não vai haver sofrimento. Há uma questão ética que é intrínseca ao processo de criação, e há a questão material também, isto é: como executar isso? Onde está a competência técnica especializada para executar esse trabalho? No entanto, tudo isto é secundário, no sentido de que os detalhes técnicos estão sempre a serviço da minha visão estética. É a minha busca estética que guia o processo de resolução material de uma obra - e nunca o contrário.

Por exemplo, no caso da criação da GFP Bunny, ${ }^{2}$ o coelho verde fluorescente, com quem estava a competência técnica?

O mundo da ciência é um mundo especializado. Um pesquisador que estuda plantas trabalha com uma espécie específica. Aquele que conhece a planta da mostarda não conhece necessariamente as características específicas da alface, do tomate etc. Um pesquisador que trabalha com coelho não conhece as particularidades do genoma do porco. O universo da ciência é muito especializado, e o artista não trabalha assim. $\mathrm{O}$ artista tem especificidades intelectuais, emocionais, filosóficas, e os instrumentos estão a serviço de uma visão maior. Move 36, por exemplo, inclui uma planta geneticamente modificada que passou por várias etapas. Criei uma seqüência genética especificamente para o trabalho, usando o código universal de computadores para traduzir a frase de Descartes "Cogito ergo sum" para as quatro bases que compõem o gene. Enviei a seqüência genética, com 52 bases, por e-mail para um pesquisador no Arizona que, por sua vez, fez a síntese. Em seguida, ele me mandou o material e eu enviei para um laboratório em Dakota do Norte. Já a seqüência do tomate, também usada para criar a planta, veio de uma Universidade da Califórnia e foi mandada para um laboratório de Dakota do Norte. Lá, pesquisadores juntaram ambas as seqüências genéticas e mandaram o material para um outro laboratório da Califórnia onde, finalmente, tudo foi integrado a uma célula de

\footnotetext{
2 Para informações sobre o trabalho GFP Bunny, consultar www.ekac.org/gfpbunny.html.
} 
planta e a transformação foi feita. Depois, as sementes foram enviadas para mim em Chicago. E por que isso? Porque cada um desses lugares tinha o conhecimento específico para fazer aquele tipo de trabalho. Sou o compositor e o maestro; fico comandando os músicos. Crio uma partitura, componho uma música e orquestro quem vai tocar qual instrumento...

Ao entrar nesse meio, você também entra em contato com uma série de regulamentações que foram criadas para esse campo específico.

Tenho permissão do Departamento de Agricultura dos Estados Unidos (USDA). ${ }^{3}$

Como foi o processo de obtenção dessa permissão?

É necessário pedir uma permissão à entidade, e explicar o que será feito. Eles então enviam a permissão, contendo um número. Mas isso não me dá liberdade para eu fazer o que quiser. É uma permissão específica para produzir aquele ser e movê-lo de um estado a outro, de forma protegida.

Você obteve essa permissão na qualidade de artista?

Sim.

Que tipo de autorização foi preciso obter, nos Estados Unidos, para realizar a planta transgênica do Move 36?

Como, no percurso do trabalho, tive de mandar a semente da planta da Califórnia para Chicago, foi necessário obter permissão para cruzar a fronteira entre estados.

Você enfrentou algum problema?

Com o Move 36, não. Mas tive problemas com o coelho de GFP Bunny, na França... Não entendo até hoje por que o diretor do laboratório francês censurou o trabalho. Talvez ele estivesse preocupado com a possibilidade de a obra ter alguma conseqüência negativa para a imagem do laboratório e assim afetasse seus negócios. Se essa preocupação se justifica ou não, se tem fundamento na realidade, é uma outra questão. Em 1948, a rádio nacional francesa encomendou a obra radiofônica Pour en finir avec le jugement de dieu de Artaud e depois, ao escutá-la, censurou-a. Hoje, essa obra é um clássico. A diferença é que, nesse caso, foi a instituição que encomendou a obra ao artista. No meu caso, foi o artista que encomendou a obra à instituição.

\footnotetext{
3 Endereço eletrônico da agência governamental mencionada: www.usda.gov/wps/ portal/usdahome.
} 
Você considera necessária a formulação de legislação específica para a manipulação de material biológico por artistas?

Não vejo necessidade de uma legislação especial para o artista. Acho que basta reconhecer o direito que o artista tem de trabalhar com materiais, materiais que se integram ao fazer da arte. Assim como o educador, ele não precisa de uma licença especial para comprar materiais liberados para uso no sistema educacional. Nos Estados Unidos existe um brinquedo para crianças acima de 10 anos que é um pequeno laboratório de biogenética, de plástico, que extrai DNA de cebola e faz outros pequenos procedimentos. Chama-se Discovery DNA Explorer Kit e custa 80 dólares. Crianças têm pequenos laboratórios de plástico em casa.

No Brasil, onde os processos de regulamentação em bioética e biossegurança foram elaborados a partir de princípios científicos, pode haver impasses no momento em que 'bioartistas' tentam justificar seus trabalhos junto a comissões de bioética. Como você avalia os formulários que os artistas, assim como os cientistas, devem preencher para obter autorização de comitês de bioética para desenvolvimento de sua obra?

Não entendo por que se pergunta qual o benefício que vai ser extraído de uma obra de arte. $\mathrm{O}$ artista pode dizer que é um benefício cultural, filosófico, de revelação de potencialidades até então não vislumbradas no campo da cultura etc. $\mathrm{O}$ artista pode preencher o formulário, mas será que o comitê de bioética vai compreender? Os pesquisadores e os artistas são profissionais de áreas distintas. Os médicos têm um vocabulário próprio para explicar fenômenos num nível de detalhe que escapa ao leigo. Toda área tem seu vocabulário próprio.

Uma das propostas do movimento Arte e Tecnologia no Brasil ${ }^{4}$ écriar, entre os segmentos artísticos passíveis de financiamento, uma categoria chamada arte e ciência, onde estariam incluídas a bioarte e a nanoarte. Nesse contexto, no qual se procura criar um espaço oficial de incentivo a esse tipo de arte, você considera importante o contato de artistas com as entidades da área de biossegurança? Você conhece movimentos semelhantes em outros países?

Nos Estados Unidos, de maneira geral, o governo só regula as instituições que recebem financiamento diretamente do governo. Ainda assim, com exceção das proibições no âmbito federal, as instituições financiadas têm a incumbência de se auto-regular. Desde que o façam, o governo não interfere. Na França, há políticas

\footnotetext{
4 Ver "Arte \& Controle de Materiais Biológicos no Brasil: Vale a Pena Dialogar?", por Dolores Galindo, disponível em www.canalcontemporaneo.art.br/tecnopoliticas/ archives/000474.html e Abaixo-assinado - Mobilização pela arte tecnológica, disponível em www.canalcontemporaneo.art.br/tecnopoliticas/archives cat_abaixoassinado_e_reunioes.htm
} 
de apoio do governo à arte criada com novos meios. Não se deve singularizar a bioarte com regras especiais, mas reconhecer a liberdade do artista para trabalhar com os materiais de sua escolha e incluir a bioarte em políticas de apoio à arte como um todo.

No caso do governo francês, isso inclui a manipulação de materiais biológicos?

Acho que não de maneira explícita. Mas também não creio que haja proibição explícita. No fundo, a bioarte é uma arte feita com um meio de criação recente. É um meio de criação que envolve a história do planeta, a vida. Os procedimentos de manipulação da vida em nível molecular direto são mais recentes. Esta é outra questão a ser discutida: o meio é a vida ou são os instrumentos de manipulação da vida? Qual o meio de criação da videoarte? São as imagens em movimento ou é toda uma série de dispositivos que permite manipular essas imagens em movimentos? Ou se poderia dizer que o meio é composto pelos dois? O meio da pintura é a tela ou a tinta? Ambos.

Você considera interessante que se promova, à medida que a bioarte passa a ser incluída como política governamental no Brasil, um espaço de discussão entre artistas e representantes da área de biossegurança?

Não sei. Não penso muito sobre essas coisas. Busco maneiras de criar meu trabalho e exibir meu trabalho, não penso muito sobre isso... Acho que há pessoas mais competentes para lidar com esse problema do que eu. Qualquer coisa que ajude, que torne a criação e a divulgação possíveis, é positivo.

Você vê o ensejo de um campo de bioarte no Brasil?

Que eu saiba, ninguém está fazendo bioarte no Brasil ainda, mas com certeza surgirão artistas que a farão.

No último prêmio Sérgio Motta de Arte e Tecnologia, realizado pelo Instituto Sergio Motta e pela Secretaria da Cultura do estado de São Paulo, houve um segmento arte e ciência, mas não foram premiados trabalhos em bioarte. Como você vê isso?

É porque não há, no Brasil, uma oferta aberta de materiais de trabalho nesta área. Os meios de produção estão concentrados em agências governamentais. Mas isso, por si só, não justifica, já que o artista poderia trabalhar em uma agência governamental. $\mathrm{O}$ artista poderia trabalhar numa universidade, assim como o artista Waldemar Cordeiro ${ }^{5}$ trabalhou com Giorgio Moscati, em 1968, na Universidade de São Paulo - USP, para fazer arte por computador.

\footnotetext{
5 Breve biografia sobre Waldemar Cordeiro pode ser obtida na Enciclopédia de artes visuais do Itaú Cultural, disponível em www.itaucultural.org.br/aplicexternas/ enciclopedia/arttec/index.cfm?fuseaction=detalhe\&cd_verbete=5932.
} 
Também não havia mercado para computadores pessoais, mas ele foi aonde o computador estava. Onde estão os procedimentos biotecnológicos no Brasil? Nas universidades. Ou seja, um artista que trabalha nessa área no Brasil tem que trabalhar numa universidade. Ele não precisa ser empregado da universidade, mas deve utilizar os recursos disponíveis naquele espaço. Outra possibilidade é trabalhar, como alguns artistas fazem nos Estados Unidos, com outras maneiras de manipular o genoma que não a engenharia genética, tais como a hibridização, uma prática muito antiga. $\mathrm{O}$ artista norte-americano George Gessert, ${ }^{6}$ por exemplo, que é o grande pioneiro da arte e genética, começou a usar a técnica da hibridização no fim dos anos 70 .

Gostaria de saber um pouco como éa sua prática no trabalho em biotecnologia, como é sua interação com cientistas, se tem enfrentado problemas, se acha importante lutar por uma legitimidade, em termos legais, da bioarte no Brasil para acesso a materiais biológicos...

Cada obra tem uma história. Cada uma é diferente da outra, em todos os sentidos.

Você poderia contar uma dessas histórias?

Minha primeira proposta de arte transgênica surgiu em 1998. Consistia em criar um cachorro fluorescente. ${ }^{7}$ Como até hoje não existe fertilização in vitro para o cachorro, minha tentativa permanece no limbo. A tecnologia não chegou aonde eu quero estar. E foi um esforço hercúleo criar, em 1998, Gênesis [obra para a qual Kac criou um gene sintético a partir da tradução de uma frase do texto bíblico, Gênesis, para o Código Morse, e da conversão do Código Morse em pares de base de DNA, seguindo um princípio de conversão desenvolvido pelo artista especialmente para esse trabalho].

\section{Como foi a criação de Gênesis?}

Trabalhei com cientistas e laboratórios comerciais. Só o gene sintético custou oito mil dólares, sem falar de todo o resto.

\section{Como obteve financiamento?}

Esses detalhes práticos da produção na minha história pessoal não têm nada de particularmente glamoroso ou curioso. Acho que isso é igual para todos. Todo mundo precisa buscar alternativas para financiar seu trabalho. Quais são as maneiras? Uma instituição

\footnotetext{
6 Ver dicionário organizado pela revista Leonardo. Informações sobre o artista estão disponíveis em mitpress2.mit.edu/e-journals/Leonardo/rolodex/gessert.george.html.

7 Kac, Eduardo. "Arte Transgênica", em Revista Ars, n. 3, 2005, publicada pela Escola de Comunicações e Artes, Universidade de São Paulo. Originalmente publicado em Leonardo Electronic Almanac, v. 6, n. 11, Dec. 1998.
} 
pode encomendar a obra e financiá-la parcialmente; o artista pode vender um trabalho; obtém apoio junto a uma fundação ou, ainda, o artista pode optar por tirar o dinheiro do próprio bolso. Pode ser também uma combinação desses recursos.

\section{E no caso do Gênesis?}

A obra foi encomendada pela mostra "Ars Eletronica", evento artístico anual realizado na Austria. Eles financiaram o trabalho.

\section{O que deve ser chamado de bioarte?}

A bioarte tem várias manifestações. Quem seria o árbitro para dar os limites? Já em 1994 comecei a trabalhar diretamente com os processos da vida, na obra Ensaio sobre o entendimento humano, e nada havia ali de transgênico. Hoje, porém, a criação de novos seres que não existem na natureza é, para mim, a região mais radical, e é por isso que ela me interessa. É a região mais controversa, menos conhecida, mais problemática, mais difícil, que envolve o elemento relacional que me interessa. Não me interessa tanto criar coisas e objetos por si só, e sim seres e relações, seres que podem estabelecer relações. Um ser vivo que tem seus próprios interesses, que tem um universo perceptivo, sensorial, cognitivo, que pode estabelecer relações baseado em seus próprios interesses e que não está condicionado pelos meus. Há, sem dúvida, outras formas de interação extremamente interessantes que não passam necessariamente pela questão da consciência como a entendemos nos animais, como no caso de nossa relação com plantas.

Você acha que conseguiria fazer no Brasil o tipo de trabalho que faz hoje?

A grande maioria dos artistas brasileiros trabalha internacionalmente. Daniel Senise ${ }^{8}$ tem ateliê em Nova York, Ernesto Neto ${ }^{9}$ e Beatriz Milhazes ${ }^{10}$ estão expondo no mundo inteiro e assim por diante. Os artistas trabalham no palco internacional. Hoje há um espaço global. $\mathrm{O}$ artista pode trabalhar, a princípio, em qualquer ambiente. Agora, se a pergunta é: “há, dentro do território geográfico da República Federativa do Brasil, recursos materiais para fazer certos tipos de trabalho?", a resposta talvez seja "não". Mas, o fato de o país participar de projetos internacionais na área de genômica talvez indique que sim. Há laboratórios de engenharia

\footnotetext{
8 Informações biográficas, alguns trabalhos e histórico de exposições podem ser acessados em www.artnet.com/artist/15325/daniel-senise.html.

${ }^{9}$ Notas sobre o artista podem ser obtidas em forumpermanente.incubadora.fapesp.br/ portal/.convidados/ernestoneto/.

10 Beatriz Milhazes por Adriano Pedrosa: disponível em www.bombmagazine.com/ milhazes/milhazes.html.
} 
genética - no Rio se criam ratos transgênicos, em São Paulo a USP desenvolve plantas transgênicas. Ou seja, certas coisas são possíveis.

Na sua avaliação, há espaço para o desenvolvimento da bioarte na comunidade acadêmica?

É como já falei. Meu empenho sempre foi o de criar a obra e também o espaço de crítica, de reflexão, através de artigos, livros, apresentações públicas e outras formas de intervenção social. Sempre tive essa preocupação. Não só fazer a obra, mas sim fazer a obra e o espaço no qual a obra vai se inserir. Essa preocupação vem não de um messianismo, de um didatismo, não é nada disso. É o reconhecimento de que, por eu estar criando algo que não existia antes, há a necessidade de criar um espaço no qual esse novo 'algo' possa existir. Se tiver essa consciência, o artista vai trabalhar para criar aquele espaço. Ao trabalhar de forma contínua, ao longo dos anos esse espaço vai surgindo. 